\section{Francisco Antonio Zea}

\section{Por el Doctor Gabriel Toro Villa}

\section{De Bogotá}

Pasma el ánimo al estudiar los héroes de la guerra de la Independencia la consideración de la maravillosa floración de genios que los acontecimientos hicieron brotar en el suelo colombiano. Falta cl tiempo para leer todo lo que nuestros grandes hicieron en esa época admirando al mundo entero que bien distinta idea tenía de los pobladores de las colonias españolas en América.

Penosa gestación en el régimen colonial preparó parte muy importante de la humanidad para exigir, llegada su hora, la emancipación; entonces á la mágica palabra de Libertad surgieron de todas partes del suelo colombiano héroes que fascinarán las generaciones y vivirán mientras el mundo exista. Caracas vio nacer á Bolívar, casi como á un predestinado, en cada palmo de esta tierra pisaba la madre de un héroe, en Medellín vino al mundo y á la inmortalidad Francisco Antonio Zea en Noviembre de 1770.

Desde muy niño fue enviado al Seminario de Popayán, al lado de su tío Don José Félix de Restrepo, entonces profesor de filosofía, amplio molde donde se formaron casi todos los intelectuales de esa época, figura ante cuya austera rectitud y espíritu justicieroreverentes tenemos que inclinamos todos los colombianos.

Condiscípulo de Camilo Torres, hizo Zea profundos estudios de latín y griego, aprendiendo á la par el francés, cosa rara en ese tiempo. Con el conocimiento de estas lenguas hizo grandes adelantos en filosofía y teología, contrayendo de preferencia su atención á la literatura, la física y las ciencias naturales.

A los 18 años de edad pasó á Bogotá al Colegio de San Bartolomé á seguir nutriendo su poderoso cerebro cursando facultades mayores. Siendo todavía estudiante fue nombrado profesor de latín. "Conocía perfectamente este idioma y los estudiantes lo veían todos los días pasearse por los claustros recitando versos de Virgilio, Ovidio y Horacio, ó suyos propios, y sonriéndose de complacencia al acabar de pronunciar el último vocablo latino. Descuidaba la compostura exterior de su persona, la limpie- za de sus miembros, el arreglo de sus cabellos, porque le parecía que quitar á los estudios unos minutos era una gran pérdida.

"Como Valenzuela, á la vez que daba lecciones las recibía del sabio Mutis, también sobre matemáticas é historia natural, y se ha dicho que fue el más notable de sus discípulos por su talento, su alma catoniana y su amor ardiente á la verdad." (Florentino Vesga, Memoria sobre el estudio de la botánica en la Nueva Granada).

Avido buscador de ciencia vio claro las mil lagunas que en el cerebro de los estudiantes se formaban por el método pedagógico usadoá la sazón; testigo presencial del rumbo que imprimía álas ideas el sabio Mutis, cuyonombre inmortal no borrará ninguna edad. (Palabras de Linneo). Con la enseñanza en el Colegio del Rosario de ciencias naturales, Zea se rebeló contra el plan de estudios vigente, que ataba las inteligencias, y á cambiarlo dedicó todos sus esfuerzos. Si no fue el iniciador de la transformación, sí fue uno de los más adeptos á ella y uno de los que hirió de muerte en la Nueva Granada la filosofía tomista y el peripato. En el Papel Periódico de Santafe protesta en razonado artículo (Hebéfilo) contra el antiguo método é invita á los jóvenes á buscar la verdadera ciencia en la contemplación de la naturaleza, en el estudio de sus secretos y sus maravillosas transformaciones; igual cosa hace en su Oración de Estudios hablando al mismo tiempo de patria en pleno régimen colonial, cuando aún estaba fresca la sangre de los Comuneros. Al pie de su último artículo hay una nota de $\mathrm{D}$. Manuel del Socorro Rodríguez que nos muestra claramente el alcance de las ideas de Zea. "Su autor es un joven que por estos ensayos ha de ser algún día no sólo un varón ilustre sino un patriota de aquellos que se complacen en sacrificar en bien de su país los bellos talentos que han recibido del Padre de las luces."

Admirado entonces, no es raro que pasara como agregado para la parte científica á la Expedición Botánica cuando contaba sólo diez y nueve años en reemplazo de D. Eloy Valenzuela. Fue uno de los más asiduos colaboradores, en la obra del ilustre Mutis, al estudio de la soberbia flora tropical; su nombre vivirá unido al del Patriarca de los botánicos, como llamó Humboldt al Jefe de la Expedición. 
Zea se hizo erudito botánico al lado de tal maestro sin olvidar los destinos del suelo que lo vio nacer, cuyas maravillas estudiaba. Frecuentaba un círculo de carácter literario que acababa de fundar Nariño cuando éste recibió los derechos del hombre, proclamados en Francia, y se dio á la gloriosa tarea de traducirlos é imprimirlos á su costa para hacerlos circular y sembrar la semilla de la libertad. En el proceso iniciado contra Nariño se halló comprometido Zea como cómplice y deportado á Españajuntamente con el precursor.

Dos años duró aherrojado en una fortaleza de Cádiz hasta que obtuvo su absolución por las influencias de algunos franceses residentes en la Corte de Carlos IV. "El Ministro Godoy, dice el historiador Plaza, descubriendo en Zea dotes nada comunes, lo hizo poner en libertad y lo envió á Francia con una misión científica y el sueldo de seis mil francos."

A su regreso de París á Madrid, al cabo de tres años, pidió permiso, que le fue negado, de volver á América, recibiendo en cambio el nombramiento de segundo y más tarde de primer Director del Gabinete Botánico de Madrid.

En esa época fue cuando dio muestras de todo su valer como científico, poniendo asímuy en alto el concepto de los intelectuales que aquende el mar se formaban. Fue miembro de la Sociedad Médica de emulación, de la Filomática, de la de Observadores del hombre.... " $d e$ cuarenta academias," dice él mismo en su carta renuncia de la Vicepresidencia de Venezuela.

Bien conocidos sus méritos, mereció el nombramiento de Profesor de botánica de la Universidad de Madrid en 1805, como sucesor del insigne Cavanilles. Al tomar posesión de su puesto pronunció un discurso inaugural sobre la utilidad de la Botánica, reputado como pieza magistral que lo realzó como naturalista y como filósofo observador. Pleito homenaje rinde Zea en el discurso al sabio Mutis, su compañero en la Expedición, su amigo, su índice y director en la corriente de sus estudios y formación de su poderosa inteligencia: "Modesto y sabio Mutis! Genio creador y benéfico! Permitidá mi corazón que os pague anticipadamente el tributo de admiración y reconocimiento debido por todo al naturalista generoso que dedica su vida y su caudal al servicio de los hombres sin exigir de ellos, como decía Séneca, más recompensa que su impunidad." (1)

No pensó Zea que al desear la impunidad para su maestro por los múltiples servicios prestados á la humanidad, á él nunca le correspondiera merecer igual suerte, por su labor en pro de la Patria que ayudó á formar y presentó á la faz del mundo civilizado. Pocos en Colombia recuerdan su labor científica y sólo hacen memoria suya para vituperar su labor diplomática, discutida y discutible aún en que el fallo de la justicia más caería sobre nosotros que no supimos mantener el legado del crédito que su amplio cerebro nos dejó después de crearlo, que en él que todolo hizo por la prosperidad y grandeza de su país.

Durante su permanencia en España redactó y colaboró en varios periódicos científicos. En sus variados artículos de entonces se encuentra gran parte de su gloria científica. En el Seminario de Agricultura hizo el empadronamiento y clasificación botánica del maíz; agradecida la ciencia llama á esta planta con el nombre del botánico antioqueño, Zea maíz, es el nombre de ese elemento precioso en la subsistencia de buena porción de la humanidad. Además escribió varias memorias sobre las quinas de la Nueva Granada y una descripción del Salto de Tequendama, que lo realza como literato y compite con los mejores que se han hecho del grandioso maltratamiento geológico, que tanto pasma los viajeros.

En 1814 pudo volver á América, bien nutrida su inteligencia con ideas grandes adquiridas en los emporios del saber, profundo conocedor de los hombres, testigo presencial de las mutaciones que producían en Europa el triunfo de la filosofía y el derecho sobre inveterados prejuicios de monarquías que se resistían á seguir la arrolladora corriente de la ciencia; y las águilas napoleónicas, cuyo vuelo victorioso borraba fronteras y destruía naciones para hacer nuevas; llegó á su Patria á luchar por la causa de la Libertad, que es la de los hombres, y por el engrandecimiento de América.

Compartió azares con Bolívar en la célebre Expedición de los Cayos, acompañándolo á Venezuela donde el

(1) Su discurso, reputado por autoridades como una gran pieza filosófica y científica, mereció los honores de la impresión del Gobierno. 
triunfo glorioso de la Revolución fue un hecho cumplido debido á la obra titánica del genio de la guerra asociado al genio político de Zea, quien fue nombrado Intendente general del Ejército independiente. Del íntimo consorcio de estos dos grandes hombres surgió la idea de formación de una vasta República con los pedazos de tierra que iban arrancando á la dominación española en nombre de la más grandiosa de las causas.

A poner la base de esa poderosa nación contribuyó Zea, prohijando el pensamiento de Bolívar en un período que, luchando con mil dificultades, fundó en Angostura, llamado Correo del Orinoco. Sus números eran un Boletín de guerra en que daba cuenta de los pasos de los ejércitos patriotas; de su pluma magistral salían artículos que á todas partes iban á inflamar el celo patriótico, á mantener vivo el fuego que los americanos habían encendido en aras de la Libertad. Conocedor de la política mundial, versado en derecho internacional, rápidamente se dio cuenta de las gestiones de España acerca de los gabinetes europeos para conseguir la intervención y así la reconquista de la importante joya que se le iba de las manos; publicó entonces su discurso sobre Mediación. Jamás verán los siglos pliego de agravios más soberbio, protesta más enérgica y ultimátum más bien razonado: “Desengáñese de una vez España; para tratar ventajosamente con la Gran Federación de América debe tratar con la opinión. No es la paz de los gabinetes sino la amistad de los pueblos la que debe poner fin á sus males."

Hizo labor fecunda por la reunión de un Congreso en que aunadas las aspiraciones de los pueblos redimidos, hicieran sus representantes una Constitución. Vio coronados sus esfuerzos con la reunión del Congreso de Angostura el 14 de Febrero de 1819. En su primera sesión, bajo la Presidencia provisional de Bolívar, fue electo verbalmente por unanimidad de votos Presidente del Congreso, y ambos, Presidente y Vicepresidente de la República de Venezuela, respectivamente. Su labor fue grande en las lides parlamentarias para hacer carta fundamental y dar leyes á una nacionalidad incipiente. La palabra de Zea sobresalía en medio de aquel grupo de oradores como sobresale el Chimborazo en medio de las alturas andinas. Después de resonar en las olas del gran río y en el follaje de los altos montes, aquellos ecos se trasmitían por las prensas del Correo del Orinoco.

Con entusiasmo trabajó en la formación de la Gran Colombia, llenodejúbilo vioalcanzado su anheloel 17 de Diciembre de 1819, en que él mismo hizo la proclamación de Colombia con las palabras históricas “La República de Colombia queda constituída. Viva la República de Colombia!".

Puso punto luminoso á sus tareas parlamentarias y á esa parte de su vida con elocuente manifiesto á los pueblos que acababan de reunir:

"Pueblos de Colombia! Un gran acto de política vanamente solicitado por hombres superiores, capaces de calcular el poder y la gloria á que podéis elevaros, reunidos bajo un Gobierno representativo y enérgico ha sido ejecutado; este acto divino, ya desde la Eternidad decretado en vuestro favor, ha venido al fin á realizarse en medio de las antiguas selvas y vastas soledades del Orinoco, bajo los auspicios del Todopoderoso. Su mano se está viendo en esta obra. Es en el seno mismo de la Naturaleza que se ha formado la República de Colombia y el sello de la creación está impreso en la ley augusta que la ha constituído.

“¡Pueblos de Venezuela que os formasteis bajo el puñal de Boves! ¡Intrépidos valientes!

“¡Pueblos de Cundinamarca que en la atroz escuela de Morillo habeis aprendido á ser libres!

“¡Pueblos de Quito que Ruiz de Castilla, aquel precursor horrible de Morillo en sangre y perfidia impelió violentamente ála Independencia!

"Vosotros todos, pueblos de Colombia! Vosotros habeis, en fin, reconocido la necesidad de reuniros en una enorme masa cuyo sólo peso oprima y hunda nuestros tiranos...".

Consumada la titánica labor de enriquecer el mundo con una nueva y vasta Nación, cuya riqueza y poderío eran difíciles de calcular, marchando unidos siempre los tres elementos que la constituyeron, Bolívar quiso predicar la buena nueva á las naciones europeas, hacerla reconocer de ellas y abrir sus inmensas riquezas naturales al comercio universal. Eligió para ello como Agente Diplomático á Francisco Antonio Zea, cerebro capaz de 
concebir la grandeza de obra que el brazo del Libertador trazaba con la espada, portavoz que con brillante elocuencia predicaba á Europa el advenimiento de Colombia al concierto de las naciones libres, en medio del fragor de las batallas. El que en 1794 fue con Nariño áEuropa como reo por la proclamación de los Derechos del Hombre, volvió en 1821 á decir al viejo continente que millones de americanos gozaban ya de esos derechos.

Pródigo Diplomático deslumbró en Europa con el lujo de su representación: "Colombia era un cadáver y yo la cubrí con un manto de oro."

Para hacer conocer las riquezas que abrigaba la República hizo un libro, en inglés y en español, titulado: Colombia, siendo una relación geográfica, topográfica, agricultural, comercial, política, etc., de aquel país. Adaptada para todo lector en general y para el comerciante y colono en particular, formando dos grandes volúmenes. Visto el mal español en que está escrito, desconociendo por eso la vasta ilustración de Zea, se ha pensado que no es suyo el libro. Otros explican los mil errores de forma, porque Zea escribió su original en francés, pagando luego un traductor que lo vertiera al español sin haber tenido él tiempo de revisar la traducción por sus múltiples ocupaciones.

No descuidó durante su misión la instrucción pública de la Patria que él contribuyó á damos. En París contrató una
Expedición científica compuesta de los señores Mariano Eduardo de Rivero, J. B. Boussingault, Doctor Roulin, Justino María Gaudot y J. Bourdon para que vinieran á difundir lasluces al pueblo que acababa de libertarse. Todos ellos eran profundos conocedores en ciencias naturales, y su obra benemérita fue la continuación de la del sabio Mutis. El Doctor Rolin vino como profesor de fisiología y anatomía, hechura suya fueron los maestros de nuestros maestros en la Facultad de Medicina.

Enfermo y agotado murió Zea en la aldea de Bath, estación balnearia, cerca á Londres, en 1822 .

“Con Zea murió, dice D. Florentino Vesga, la última esperanza que pudiera haberse tenido sobre readquirir las colecciones y manuscritos de la Expedición Botánica ó hacer que la ciencia aprovechara esos materiales tan preciosos. En efecto, como ya se ha dicho, él había sido el segundo compañero del gran Mutis, y por la índole de sus funciones, como tal una buena parte de sus manuscritos debían proceder de su pluma...

"Y qué fecundo en resultados hubiera sido el que el gran Zea, cuyas lecciones no dejaban que envidiar cuando su voz resonaba en la Universidad y Real Jardín Botánico de Madrid, hubiese enaltecido con ellos el nombre de Colombia, y restablecido en su país, de rica naturaleza, ese gusto y ese entusiasmo por ella, apagados cruelmente por la cuchilla pacificadora!".

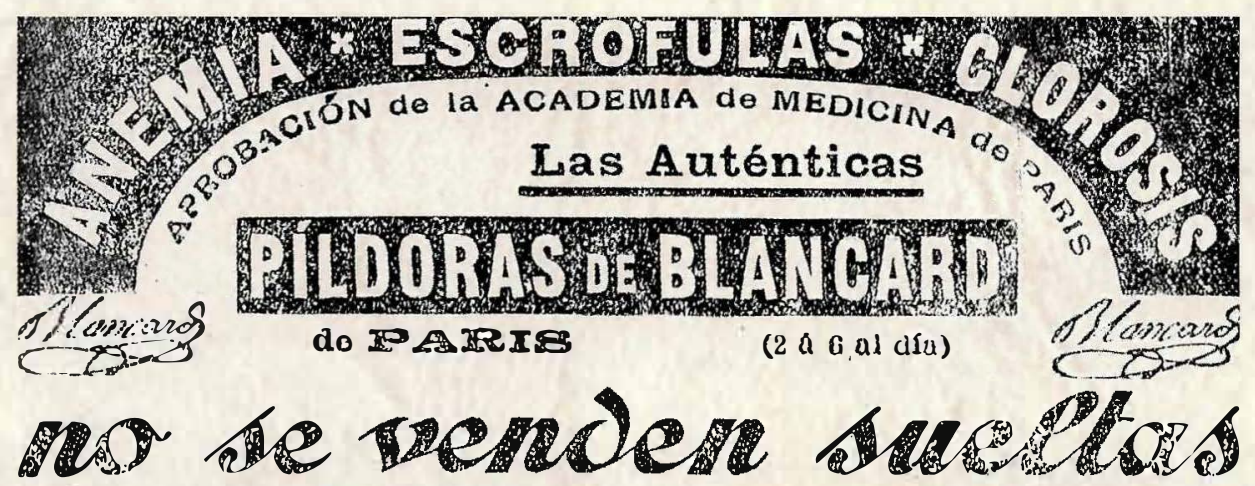

Exijanse la Firma y el Rótulo verdo

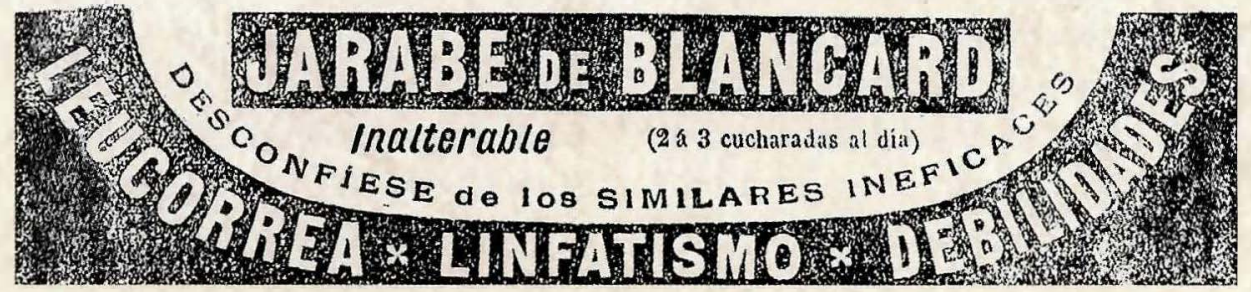

Reproducción del aviso publicado en Repertorio de Medicina y Cirugía volumen II Número 4 de enero 15 de 1911. 